were enrolled; 64.9\% women; mean (SD) age 75 (8.9) years; median [IQR] TAB length $17.5[13.0,20.0] \mathrm{mm}$; headache $54.1 \%$; jaw claudication $45.9 \%$; scalp tenderness $16.2 \%$; temporal artery (TA) tenderness $32.4 \%$; TA engorgement $32.4 \%$; TA pulse abnormality $5.4 \%$; visual symptoms $2.7 \%$; a fever of $38.5^{\circ} \mathrm{C}$ or higher $40.5 \%$; shoulder girdle pain $48.6 \%$; imaging of aortitis or arteritis $40.5 \%$; median [IQR] white blood cell 9,100 [7200, 12050]/ $\mathrm{l}$; median [IQR] platelet cell 37.5 [27.0, 46.3] $\times 10^{4} / \mu \mathrm{l}$; median [IQR] C-reactive protein (CRP) $10.1[3.9,16.5] \mathrm{mg} / \mathrm{dL}$; erythrocyte sedimentation rate [IQR] $105[66,129] \mathrm{mm} / \mathrm{h}$. Thirty-one in 37 cases were positive bilaterally while 6 in 37 cases were positive unilaterally; and the discordance rate was $16.2 \%$. The median sample length after formalin fixation was $19.0 \mathrm{~mm}$ for the BPG and $14.5 \mathrm{~mm}$ for the UPG $(p=0.171)$. The parameters above were compared between UPG and BPG. Of these, only the serum CRP value $(\mathrm{mg} / \mathrm{dL})$ differed statistically between groups, and the median value of the two groups was 10.6 and 6.5 , respectively (median test: $p=0.031$ ). To predict $B P G$, in whom unilateral TAB is sufficient for diagnosing GCA, the cut-off value of serum CRP with a specificity of $100 \%$ and a sensitivity of $61.3 \%$ was set at $9.3 \mathrm{mg} / \mathrm{dL}$ (ROC analysis: AUC 0.726).

Conclusion: When the serum CRP level is $10 \mathrm{mg} / \mathrm{dL}$ or higher in GCA suspected patients, an unilateral TAB alone was sufficient for an accurate diagnosis.

References:

[1] Hellmich, B, et al. Ann Rheum Dis 2020;79(1):19-30

[2] Breuer, GS, et al. J Rheumatol. 2009;36(4):794-796.

[3] Czyz CN, et al. Vascular 2019;27(4):347-351.

[4] Durling B, et al. Can J Ophthalmol 2014;49(2):157-161.

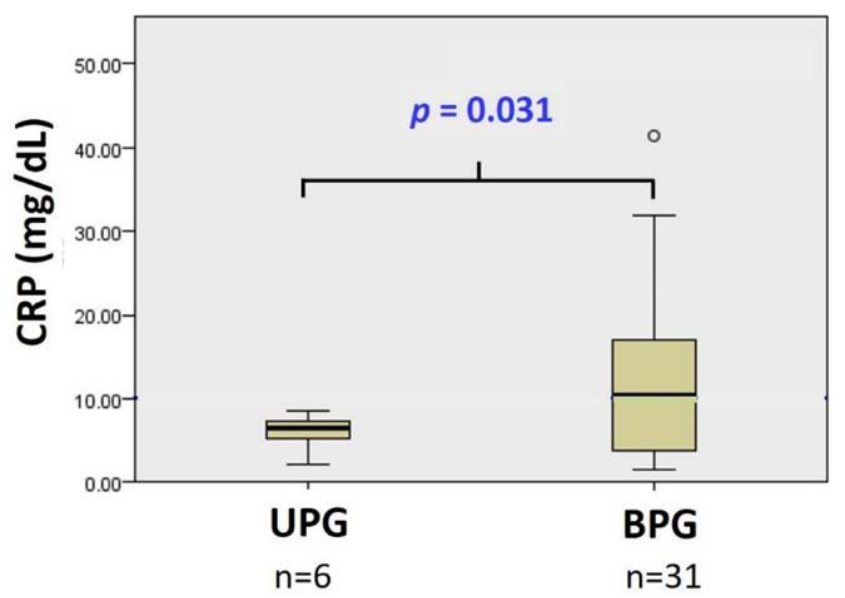

Figure. Comparison of median CRP levels between unilaterally positive group and bilaterally positive group.

Disclosure of Interests: None declared

DOI: 10.1136/annrheumdis-2020-eular.458

\section{THU0310 CASE-CONTROL SEROPREVALENCE STUDY ON THE ASSOCIATION BETWEEN BARTONELLA INFECTION AND ANTI-NEUTROPHIL CYTOPLASMIC ANTIBODY- ASSOCIATED VASCULITIS}

A. Mahr ${ }^{1}$, S. Edouard ${ }^{2}$, D. Cornec ${ }^{3}$, S. Gonzalez-Chiappe ${ }^{4}$, J. Goronzy ${ }^{5}$, P. Guilpain ${ }^{6}$, C. Langford ${ }^{7}$, P. Y. Lévy², P. A. Merkel ${ }^{8}$, P. Monach ${ }^{9}$, E. W. St. Clair ${ }^{10}$, P. Seo ${ }^{11}$, R. Spiera ${ }^{12}$, C. Weyand ${ }^{5}$, J. H. Stone ${ }^{13}$, D. Rauolt ${ }^{2}$, U. Specks ${ }^{14} .{ }^{1}$ Kantonsspital St. Gallen, St. Gallen, Switzerland; ${ }^{2}$ Hospital La Timone, Marseille, France; ${ }^{3}$ Université de Bretagne Occidentale, CHU de Brest, Brest, France: ${ }^{4}$ Hospital Saint-Louis, Paris, France: ${ }^{5}$ Stanford University, Stanford, United States of America; ${ }^{6}$ Hospital Saint-Eloi, Montpellier, France; ${ }^{7}$ Cleveland Clinic, Cleveland, United States of America; ${ }^{8}$ University of Pennsylvania, Philadelphia, United States of America; ${ }^{9}$ Brigham and Women's Hospital, Boston, United States of America; ${ }^{10}$ Duke University Medical Center, Durham, United States of America; ${ }^{11}$ Johns Hopkins University, Baltimore, United States of America; ${ }^{12}$ Hospital of Special Surgery, New York, United States of America; ${ }^{13}$ Massachussetts General Hospital, Boston, United States of America; ${ }^{14}$ Mayo Clinic, Rochester, United States of America

Background: Bartonellosis is an emerging anthropozoonosis caused by infection with intracellular Gram-negative Bartonella species. It leads to necrotizing granulomas and endothelial damage and causes acute and chronic human diseases, such as cat scratch disease, bacillary angiomatosis and endocarditis. Endocarditis due to Bartonella henselae and B. quintana is reported to produce anti-neutrophil cytoplasmic antibodies (ANCAs) that disappear with effective antimicrobial treatment.

Objectives: Hypothesizing a role for Bartonella infection in ANCA-associated vasculitis (AAV), which also includes granulomatous and vascular inflammation, we studied the seroprevalence of 5 Bartonella species in patients with AAV.

Methods: The study used plasma samples from patients with granulomatosis with polyangiitis and microscopic polyangiitis that were enrolled in the Rituximab for AAV (RAVE) trial and from healthy controls living in the United States. Western blot assays were used for serological testing of infection with B. quintana, B. henselae Houston-1, B. elizabethae, B. vinsonii subsp. berkhoffii and $B$. alsatica. The associations of positive serology results and AAV were expressed as odds ratios (OR). Clinical characteristics of seropositive and seronegative patients, assessed by the BVAS/WG instrument, were compared. These comparisons were done for 9 organ systems; in case they showed differences with $P<0.10$, the corresponding organ system-specific clinical features were also analyzed. Statistical analysis was performed using Fisher's exact test or Student's t-test, as appropriate.

Results: We analyzed blood samples of 187 patients with AAV (collected at start of the trial) and of 127 controls. There were no significant differences between the cases and controls for mean age $(P=0.148)$ and proportion of males $(P=0.36)$ Bartonella spp. serological testing was positive for $112(60 \%)$ cases and 40 (31\%) controls (OR 3.25 [95\% Cl 2.02-5.22], $P<0.001$ ). Significant associations were also found within subsets of PR3-AAV (OR 4.00 [95\% Cl 2.37-6.76] $P<0.001$ ), MPO-AAV (OR 2.18 [95\% Cl 1.17-4.06], $P=0.017$ ), newly-diagnosed (OR 3.89 [95\% Cl 2.21-6.86], $P<0.001$ ) and relapsing disease (OR 2.86 [95\% Cl 1.65-4.98], $P<0.001)$. Species-specific positive serological testing was found in particular against $B$. henselae (cases: $27 \%$, controls: 0.8\%; OR 39.93 [95\% C 5.42-293.90]; $P<0.001$ ). Compared to AAV patients without seropositivity for Bartonella spp., AAV patients testing seropositive for Bartonella spp. had significantly more bloody nasal discharge $(P=0.046)$, sinus involvement $(P=0.035)$ and conjunctivitis/episcleritis $(P=0.016)$

Conclusion: This study reveals higher seroprevalence of Bartonella, especially $B$. henselae, in patients with AAV than in healthy controls. Although cross-reactivity of Bartonella with other microorganisms cannot be excluded, these results may support an etiopathogenic role of Bartonella infection in AAV that deserves further investigation.

Disclosure of Interests: Alfred Mahr Consultant of: Celgene, Speakers bureau Roche, Chugai, Sophie Edouard: None declared, Divi Cornec: None declared, Solange GONZALEZ-CHIAPPE: None declared, Jörg Goronzy: None declared Philippe Guilpain: None declared, Carol Langford: None declared, Pierre-Yves Lévy: None declared, Peter A. Merkel: None declared, Paul Monach: None declared, E. William St. Clair: None declared, Philip Seo: None declared, Robert Spiera Grant/research support from: Roche-Genetech, GSK, Boehringe Ingelheim, Chemocentryx, Corbus, Forbius, Sanofi, Inflarx, Consultant of Roche-Genetech, GSK, CSL Behring, Sanofi, Janssen, Chemocentryx, For bius, Mistubishi Tanabe, Cornelia Weyand: None declared, John H. Stone Grant/research support from: Roche, Consultant of: Roche, Didier Rauolt: None declared, Ulrich Specks: None declared

DOI: 10.1136/annrheumdis-2020-eular.3361

\section{THU0311 CERTOLIZUMAB THERAPY IN REFRACTORY UVEITIS DUE TO IMMUNE-MEDIATED INFLAMMATORY DISEASES (IMID). MULTICENTER STUDY OF 39 PATIENTS}

J. L. Martín-Varillas ${ }^{1}$, V. Calvo-Río ${ }^{2}$, L. Sanchez-Bilbao² ${ }^{2}$ I. González-Mazón ${ }^{2}$, I. Torre-Salaberri ${ }^{3}$, Á. García Martos ${ }^{4}$, A. Sanchez-Andrade ${ }^{5}$, Á. GarcíaAparicio $^{6}$, J. De Dios-Jiménez Aberásturi ${ }^{7}$, A. Urruticoechea-Arana ${ }^{8}$, O. Maíz ${ }^{9}$, R. Veroz Gonzalez ${ }^{10}, A$. García-Valle ${ }^{11}$, S. Rodríguez Montero ${ }^{12}$ R. Miguélez ${ }^{6}$, V. Jovani ${ }^{13}$, M. Hernández-Garfella ${ }^{14}$, A. Conesa ${ }^{15}$, O. Martínez González $^{16}$, P. Rubio Muñoz ${ }^{17}$, B. Atienza-Mateo ${ }^{2}$, M. A. González-Gay², R. Blanco ${ }^{2} .{ }^{1}$ H. Sierrallana, Torrelavega, Spain; ${ }^{2}$ H.U.M. Valdecilla, Santander, Spain; ${ }^{3} \mathrm{H}$. Basurto, Bilbao, Spain; ${ }^{4} \mathrm{H}$. Tajo, Madrid, Spain; ${ }^{5} \mathrm{H}$. Lucus Augusti, Lugo, Spain; ${ }^{6}$ H. Toledo, Toledo, Spain; ${ }^{7}$ H. Álava, Álava, Spain; ${ }^{8}$ H. Can Misses, Ibiza, Spain; ${ }^{9} \mathrm{H}$. Donosti, San Sebastian, Spain; ${ }^{10} \mathrm{H}$. Mérida, Mérida, Spain; ${ }^{11} \mathrm{H}$. Palencia, Palencia, Spain; ${ }^{12} \mathrm{H}$. Valme, Sevilla, Spain; ${ }^{13} \mathrm{H}$. Alicante, Alicante, Spain; ${ }^{14}$ H.G. Valencia, Valencia, Spain; ${ }^{15} \mathrm{H}$. Castellón, Castellón, Spain; ${ }^{16} \mathrm{H}$. Salamanca, Salamanca, Spain; ${ }^{17} \mathrm{H}$. Esperit Sant, Barcelona, Spain

Background: Infliximab and adalimumab therapy has significantly improved the prognosis of patients with non-infectious refractory uveitis. However, there is not enough evidence for the use of other anti-TNF drugs such as Certolizumab Pegol (CZP).

Objectives: To evaluate the efficacy and safety of CZP in uveitis secondary to Immune-Mediated Inflammatory Diseases (IMID). 
Methods: Multicenter study of 39 patients with uveitis due to IMID refractory to glucocorticoids and conventional immunosuppressants. Efficacy of CZP was evaluated with the following ocular parameters: best corrected visual acuity (BCVA), anterior chamber cells, macular thickness and presence of retinal vasculitis. Efficacy of CZP was compared between baseline, 1st week, 1st and 6th month, and 1st and 2nd year. Statistical analysis was performed with the STATISTICA software (Statsoft Inc. Tulsa, Oklahoma, USA).

Results: 39 patients/56 affected eyes (18 men/21 women) with a mean age of $40.5 \pm 11.9$ years were studied. IMIDs included were: spondyloarthritis $(n=17)$, psoriatic arthritis (6), Crohn (3), JIA (2), Behçet (2), reactive arthritis (2), rheumatoid arthritis (1), relapsing polychondritis (1), pars planitis (1), Birdshot (1) and idiopathic uveitis (3). Uveitis pattern was as follows: anterior $(n=30)$, posterior $(4)$, panuveitis (3) and intermediate (2)

Previous CZP, patients received: oral prednisone $(n=18)$ methylprednisolone bolus (1), methotrexate (22), azathioprine (10), cyclosporine (4), leflunomide (2), mycophenolate mofetil (2) and cyclophosphamide (1). $77 \%$ of patients had received previous biological therapy, with a mean of $1.6 \pm 1.2$ biological drugs per patient. Gestational desire was the reason for prescribing CZP in 8 patients. CZP was administered in monotherapy in 16 patients and in the remaining 23 patients combined with conventional immunosuppressants.

After a median follow-up of 24 [6-36] months, most of the ocular variables analysed showed a rapid and significantly sustained improvement (Table). CZP was discontinued in 11 patients for the following reasons: remission $(n=1)$, insufficient response of ocular symptoms $(n=1)$ and limited response of extraocular manifestations $(n=9)$. No serious adverse effects were reported.

Conclusion: CZP seems to be effective and safe in patients with refractory uveitis due to IMID.

Table

\begin{tabular}{lcccccc}
\hline & Baseline $1^{\text {st }}$ week & $1^{\text {st }}$ Month & $6^{\text {th }}$ Month $1^{\text {st }}$ year & $2^{\text {nd }}$ year \\
\hline BCVA (mean \pm SD) & $0.77 \pm 0.290 .77 \pm 0.30^{*}$ & $0.82 \pm 0.29^{*}$ & $0.85 \pm 0.26^{*}$ & $0.86 \pm 0.27^{*}$ & $0.88 \pm 0.23^{*}$ \\
Tyndall (median [IQR $])$ & $0[0-2]$ & $0[0-2]$ & $0[0-1]^{*}$ & $0[0-0]^{*}$ & $0[0-0]^{*}$ & $0[0-0]^{*}$ \\
OCT (mean \pm SD) & $355 \pm 61.5$ & - & $284.1 \pm 40.4^{*}$ & - & $224.8 \pm 121.1^{*}$ & - \\
Retinal Vasculitis & $2(3.6)$ & $0(0)$ & $0(0)$ & $0(0)$ & $0(0)$ & $0(0)$ \\
(eyes affected, \%) & & & & & & \\
\hline
\end{tabular}

${ }^{*} \mathrm{p}<0.05$

Disclosure of Interests: José Luis Martín-Varillas Grant/research support from: AbbVie, Pfizer, Janssen and Celgene, Speakers bureau: Pfizer and Lilly, Vanesa Calvo-Río Grant/research support from: MSD and Roche, Speakers bureau: AbbVie, Lilly, Celgene, Grünenthal, UCB Pharma, Lara Sanchez-Bilbao Grant/ research support from: Pfizer, Iñigo González-Mazón: None declared, Ignacio Torre-Salaberri: None declared, Álvaro García Martos: None declared, Amalia Sanchez-Andrade: None declared, Ángel García-Aparicio: None declared, JR De Dios-Jiménez Aberásturi: None declared, ANA URRUTICOECHEA-ARANA: None declared, Olga Maíz: None declared, Raul Veroz Gonzalez: None declared, Andrea García-Valle: None declared, Sergio Rodríguez Montero: None declared, Roberto Miguélez: None declared, Vega Jovani: None declared, Marisa Hernández-Garfella: None declared, Arantxa Conesa: None declared, Olga Martínez González: None declared, Paula Rubio Muñoz: None declared, Belén Atienza-Mateo: None declared, Miguel A González-Gay Grant/research support from: Pfizer, Abbvie, MSD, Speakers bureau: Pfizer, Abbvie, MSD, Ricardo Blanco Grant/research support from: AbbVie, MSD, and Roche, Speakers bureau: AbbVie, Pfizer, Roche, Bristol-Myers, Janssen, and MSD DOI: 10.1136/annrheumdis-2020-eular.6367

\section{\begin{tabular}{|l|l}
\hline THU0312 & AUTOLOGOUS NON-MYELOABLATIVE
\end{tabular} HEMATOPOIETIC STEM CELL TRANSPLANTATION FOR REFRACTORY TAKAYASU ARTERITIS: A RETROSPECTIVE MULTICENTRE CASE-SERIES FROM THE AUTOIMMUNE DISEASES WORKING PARTY (ADWP) OF THE EUROPEAN SOCIETY FOR BLOOD AND MARROW TRANSPLANTATION (EBMT)}

C. Laurent ${ }^{1}$, Z. Marjanovic ${ }^{2}$, J. Henes ${ }^{2}$, D. Farge ${ }^{2}$, M. Badoglio ${ }^{2}$, J. Snowden $^{2}$, O. Fain ${ }^{2}$, T. Alexander ${ }^{2}$, M. C. Oliveira ${ }^{2}$, A. Mekinian ${ }^{1}$ on behalf of no. ${ }^{1}$ Hopital $^{2}$ Saint Antoine, Paris, France; ${ }^{2}$ Saint Louis, Paris, France

Background: Takayasu arteritis (TAK) is a chronic granulomatous large-vessel vasculitis, characterized by arterial thickening and fibrosis leading to stenosis and vascular occlusions. More than $10-20 \%$ of patients are refractory to conventional immunosuppressive therapy. Autologous hematopoietic stem cell transplantation (AHSCT) has emerged as a promising treatment option in severely affected and refractory patients with various autoimmune diseases and vasculitis, particularly ANCA-positive vasculitis and Behçet's disease.
Objectives: This study, approved by the ADWP, aims to evaluate the use and outcome of AHSCT in adult TAK patients.

Methods: This is a retrospective survey of patients reported to the EBMT registry between 1998 and 2019, who received AHSCT primarily for TAK. Clinical and laboratory data, including data on diagnosis, previous lines of therapy, transplant regimen, treatment-related mortality, as well as data regarding course of disease and treatment were recorded.

Results: Data from six adult patients treated with AHSCT between 2003 and 2019 for refractory Takayasu have been identified. Median (ranges) follow-up was 9.9 (1-14) years. Five patients were female (83\%), median age was 25 (9-39) years at diagnosis and $28(22-41)$ years at HSCT. All patients were pretreated with a median of 6 (4-8) lines of therapy, including systemic steroids ( 6 patients), methotrexate (5 patients), cyclophosphamide, mycophenolate mofetil or infliximab (4 patients), tocilizumab or etanercept (2 patients), and other biologic or conventional-synthetic DMARDs. Conditioning included cyclophosphamide and rabbit anti-thymocyte globulin in all patients. At six months post-transplantation remission was obtained in all cases, which persisted at 12 months in 5 cases Four patients reactivated TAK at a median time of 27 (7-52) months after AHSCT, and 3 resumed disease-modifying therapy. At last follow-up, all patients were alive, 2 patients were in remission (off-therapy), 2 patients improved compared to baseline, and 2 patients were in complete and partial remission, respectively, under immunosuppressive treatment.

Conclusion: This small retrospective series demonstrates that AHSCT has the potential to provide significant clinical responses in TAK patients who had been unresponsive to previous immunosuppressive therapy, with an acceptable safety profile.

Acknowledgments: no

Disclosure of Interests: CHARLOTTE LAURENT: None declared, ZORA MARJANOVIC: None declared, Jörg Henes Grant/research support from: Novartis, Roche-Chugai, Consultant of: Novartis, Roche, Celgene, Pfizer, Abbvie Sanofi, Boehringer-Ingelheim,, DOMNIQUE FARGE: None declared, MANUELA BADOGLIO: None declared, John SNOWDEN: None declared, olivier fain: None declared, Tobias Alexander: None declared, Maria Carolina Oliveira: None declared, Arsene Mekinian: None declared

DOI: 10.1136/annrheumdis-2020-eular.3501

\section{THU0313 \\ DISEASE PATTERN AND TIME TO DIAGNOSIS IN A FAST-TRACK GIANT CELL ARTERITIS CLINIC USING ULTRASOUND AS PRIMARY DIAGNOSTIC TOOL}

$\underline{U}$. Møller Døhn ${ }^{1,2}$, V. Fana ${ }^{1,2}$, T. Møller ${ }^{1}$, J. J. Lykkegaard ${ }^{1}$, L. Terslev ${ }^{1,2}$

${ }^{1}$ Rigshospitalet, Glostrup, Center for Rheumatology and Spine Diseases, Glostrup, Denmark; ${ }^{2}$ Rigshospitalet, Glostrup, Copenhagen Center for Arthritis Research, Glostrup, Denmark

Background: Giant Cell Arteritis (GCA) is a vasculitis predominantly affecting the large vessels from aorta and its proximal branches and extra-cranial arteries. Precise and fast diagnosis is important in order to initiate proper treatment and avoid ischaemic events, e.g. irreversible visual loss. Unnecessary and prolonged glucocorticoid treatment is also unwanted due to its significant side effects. Therefore, immediate diagnosis of GCA is recommended, and the primary diag nostic tool, according to EULAR recommendation, is vascular ultrasound (US) ${ }^{1}$ In 2018, a GCA Fast-Track Clinic (FTC) was implemented in our department covering a population of approximately 900.000 . Patients even with a low á-priori suspicion of GCA were accepted. It is the aim to have patients seen within one office day.

Objectives: In this retrospective study, to describe clinical data from patients seen in the FTC in a 1-year period from September $1^{\text {st }}, 2018$ and to investigate the time required for making a diagnosis, and to which extent US as the primary diagnostic tool was adequate for making the final diagnosis

Methods: All patients, irrespective of clinical presentation, had US of bilateral temporal-, facial-, axillary and common carotid arteries done (exam time $30 \mathrm{~min}$.). All US were done by ultrasonographers with experience and training in vascular US. Immediately after the initial US, patients were seen by a senior registrar in rheumatology at our out-patient clinic. The senior registrar was aware of the conclusion of the US. Decisions on further diagnostic procedures were solely up to this rheumatologist. From electronic patient report files, all patients' clinical- and US-findings as well as results from other diagnostic procedures (temporal artery biopsy (TAB) and positron emission tomography computed tomography (PET-CT)) were evaluated. Furthermore, final diagnosis and fulfilment of ACR1990 classification criteria for temporal arteritis at three months was noted, as was the number of days required for diagnosis.

Results: A total of 120 patients were seen in the FTC and had a vascular US done. Demographic and clinical data are seen in table 1. Of 120 patients, 42 (35\%) had a clinical diagnosis of GCA at three months and 42\% fulfilled ACR1990 criteria for temporal arteritis. Based on US alone, $36 \%$ of patients had GCA. A 